\title{
Socioeconomic Status is not associated with Type 2 Diabetes Incidence in an Elderly Population in Germany: KORA S4/F4 Cohort Study
}

Bernd Kowall ${ }^{1}$, Wolfgang Rathmann ${ }^{1}$, Klaus Strassburger ${ }^{1}$, Christine Meisinger ${ }^{2}$, Rolf Holle ${ }^{3}$, Andreas Mielck $^{3}$

${ }^{1}$ Institute of Biometrics and Epidemiology, German Diabetes Center, Leibniz Center for Diabetes Research at Heinrich Heine University, Düsseldorf, Germany

${ }^{2}$ Helmholtz Zentrum München, National Research Center for Environmental Health, Institute of Epidemiology, Neuherberg, Germany

${ }^{3}$ Helmholtz Zentrum München, National Research Center for Environmental Health, Institute of Health Economics, Neuherberg, Germany

Word count: abstract: 246 words; text: 3,314 words

4 tables, 30 references

\section{Correspondence to}

Dr. med. W. Rathmann MSPH (USA)

German Diabetes Center

Institute of Biometrics and Epidemiology

Auf'm Hennekamp 65

40225 Düsseldorf, Germany

Fon: ++49 $2113382-663$

Fax: ++49 $2113382-677$

Email: rathmann@ddz.uni-duesseldorf.de 
The Corresponding Author has the right to grant on behalf of all authors and does grant on behalf of all authors, an exclusive licence on a worldwide basis to the BMJ Publishing Group Ltd and its Licencees to permit this article (if accepted) to be published in JECH and any other BMJPGL products to exploit all subsidiary rights, as set out in our licence. 


\begin{abstract}
Background

An association between socioeconomic status (SES) and incidence of type 2 diabetes mellitus (T2DM) has been found for younger and middle-aged subjects, but studies of this relationship in elderly populations are rare.
\end{abstract}

\title{
Methods
}

In a population-based cohort in Southern Germany (KORA S4/F4: 1,223 subjects aged 55-74 years at baseline, 887 subjects (73\%) in the follow-up seven years later), identification of incident T2DM was based on oral glucose tolerance tests or on validated physician diagnoses. Regression models were fitted to predict incident T2DM and (pre)diabetes respectively, with SES as the main independent variable. (Pre)diabetes here means incident T2DM or incident prediabetes.

\section{Results}

With five different SES measures (global Helmert index, income, educational level, occupational status, subjective social status), the diabetes risk of low SES groups was not significantly different from the risk of higher SES groups (i.e., cumulative incidence 10\% (low income), 9\% (medium income), $13 \%$ (high income)). In subjects with normoglycemia at baseline, (pre)diabetes incidence was more pronounced in lower SES groups, but almost all these associations were not significant. With measures of subjective SES stronger associations were found than with measures of objective SES.

\section{Conclusion}

There was no statistically significant association between objective SES and diabetes incidence in this elderly population. This might be due to a larger socioeconomic homogeneity of elderly populations and to a strong driving force for diabetes, which outweighed the influence of SES, and which was indicated by an adverse baseline metabolic profile in participants developing diabetes in the follow-up. 
Keywords: Type 2 diabetes, prediabetes, socioeconomic status, elderly population

\begin{abstract}
Abbreviations:
T2DM, type 2 diabetes mellitus; SES, socioeconomic status; OGTT, oral glucose tolerance test; IFG, impaired fasting glucose; IGT, impaired glucose tolerance; CI, confidence interval; OR, odds ratio.
\end{abstract}




\section{Introduction}

Previous studies have shown an inverse association between measures of socioeconomic status (SES) and incidence of type 2 diabetes (T2DM).[1-15] However, most of these studies did not use oral glucose tolerance tests (OGTT) to identify diabetes cases.[3, 5, 7-11, 15] Other studies did not measure the SES on an individual level, $[1,12]$ or only used "type of neighborhood" as predictor variable.[6] Furthermore, some were confined to very specific populations like nurses or male factory workers.[4, 13] In particular, there is only little evidence whether the inverse association between SES and diabetes incidence also holds for elderly populations, and with few exceptions $[8,11]$ the studies examined populations of younger or middle-aged subjects, or they comprised several age groups. In most studies, education $[2,3,5,8,9-11,13,14]$ and occupational status $[4,7,10,13,14]$ were used as measures of SES, while income [8-10] was used less often. However, indices of SES measure different aspects of the mechanisms between SES and health outcomes and they cannot be used interchangeably.[16] Moreover, the association between the subjective SES and T2DM has only rarely been investigated in the elderly.[17]

This study used data of a population-based cohort of elderly subjects to examine the relationship between objective and subjective SES, respectively, and diabetes incidence. Most incident diabetic cases in KORA S4/F4 were prediabetic at baseline.[18] To examine additionally the relationship between social status and diabetes in subjects who were normoglycemic at baseline we chose (pre)diabetes - (pre)diabetes here means incident type 2 diabetes or prediabetes - as outcome variable for two reasons: with T2DM cases as outcome, the power of the analyses with normoglycemic subjects might be too small; and, moreover, analyses should not be confined to T2DM because prediabetes already increases the risk for coronary heart disease and is often associated with an unfavorable metabolic profile.[19] We used OGTT to identify new diabetes cases, and we used income, education and occupational status separately as SES measures in addition to an SES measure combining these three indicators. 


\section{Methods}

\section{Study population}

The KORA (Cooperative Health Research in the Region of Augsburg) Survey is a population-based study in Southern Germany using the same region and study methods as the previous WHO MONICA Augsburg project. 2,656 subjects in the age of 55 to 74 years were invited to participate in 1999, and 1,653 (62\%) subjects were investigated. 131 subjects with known diabetes were excluded, and after exclusion of further drop-outs 1,353 nondiabetic subjects underwent an OGTT at baseline. This recruitment process has been described in more detail earlier.[19]

All subjects with completed OGTT at baseline were re-invited in 2006 to 2008 . The present study includes all subjects without known or newly diagnosed diabetes at baseline $(n=1,223)$. Among these subjects, 98 had died before the time of the follow-up examination, and 887 (73\%) subjects participated in the follow-up. Informed consent was obtained from the participants. The survey was approved by the ethics committee of the Bavarian Medical Association.

\section{Definition of SES variables}

SES indicators were assessed in a structured health interview performed by trained investigators. Scores for educational level, occupational status and income were assigned based on a scheme developed by Helmert for the German population.[20, 21] The highest score either for school education or vocational training was used for the educational level. School education was based on the highest level obtained (primary, secondary, tertiary school or university degree), and three categories for vocational training were distinguished. Subjects' reported occupations were grouped in a social class hierarchy proposed by Helmert and Sheafor the German labour market.[22] For retired persons, their latest occupation was coded. Among persons without regular employment (e.g. housewives) the 
occupation of the spouse was used as a proxy. Equivalent household income was categorized as less than $50 \%, 50-100 \%, 101-150 \%, 151-200 \%$, and more than $200 \%$ of the median income. Scores ranged from 1 to 9 (income, occupation), and 0 to 9 (education), respectively, and were added up to build a global score for SES.

For regression analyses, subjects were grouped into three categories for the global SES as well as for educational level, occupational status and income. According to the literature,[21] these categories were the following for the global SES: low SES = scores from 2 to 8; medium SES = scores from 9 to 18; high SES = 19 to 27. For education, occupation and income, categories were as follows: scores up to $3=$ low status; scores from 4 to $6=$ medium status; scores from 7 to $9=$ high status.

To assess subjective SES, subjects were asked to which social class they belonged in their own view. Categories were combined as follows: low subjective status (lower or working class), medium subjective status (medium class), high subjective status (upper medium or upper class).

\section{Ascertainment of type 2 diabetes and prediabetes}

Subjects who reported a physician diagnosis of diabetes or use of anti-diabetic medications were classified as incident diabetes cases, their reports were validated by contacting the general practitioners who had treated them. For the remaining subjects, OGTT with a $75 \mathrm{~g}$ oral load of anhydrous glucose were conducted to ascertain diabetes status. OGTT were performed in the morning hours $(7: 00$ to 11:00 h). Subjects were instructed to fast for 10 hours overnight, to avoid heavy physical activity and not to smoke before or during the OGTT. Subjects with fever, infections or acute gastrointestinal diseases were excluded from the test. Impaired fasting glucose, impaired glucose tolerance and newly diagnosed diabetes were defined according to 1999 WHO criteria.[23] Prediabetes comprised isolated IFG, isolated IGT and combined IFG and IGT. Newly diagnosed type 2 diabetes (OGTT) and validated physician diagnosis were considered as incident type 2 diabetes. 
Anthropometric measurements and laboratory measurements have been described elsewhere.[20] Information about sociodemographic variables, medical history, smoking, alcohol consumption, and physical activity was gathered in a structured interview. Dietary intake was assessed with a short 27 item qualitative food frequency list (FFL). Details on a very similar FFL have been described elsewhere.[24]

\section{Statistical analysis}

Baseline characteristics of subjects with low, medium or high global SES were compared using F-tests or $\chi^{2}$-tests. For subjects with and without diabetes in the follow-up, medians of the Helmert SES scores were compared using the Mann-Whitney U-test. For all subjects, the proportion of incident diabetes cases, and for the subgroup of subjects with normoglycemia at baseline, the proportion of incident (pre)diabetes cases was calculated for each level of the different SES measures. Significance of differences in these proportions between SES levels was tested using $\chi^{2}$-tests.

Multivariate logistic regression models were fitted to calculate odds ratios with $95 \%$ confidence intervals for the relationship between SES variables and diabetes or (pre)diabetes. Five different SES measures (global SES, educational level, occupational status, income, and subjective social status) were used separately in each set of analyses. In a first set of analyses, all 887 subjects were included, and the association between SES and the incidence of diabetes was assessed. In a second set of analyses, only subjects with normoglycemia (no prediabetes) at baseline were considered, and the relationship between SES and the incidence of (pre)diabetes was assessed. As there is some evidence for a gender-specific SES-diabetes relationship, $[8,2526]$ interaction terms (interaction between SES and sex) were tested for significance, and analyses were additionally done separately for men and women.

Covariables considered either as potential confounders or as possible mediators of the association between SES and diabetes or (pre)diabetes were included in the regression models. For the two sets of 
analyses (with diabetes or (pre)diabetes as outcome variables), three different models were examined: (1) models adjusted only for age and sex as possible confounders; (2) models additionally adjusted for age, sex, and lifestyle factors (smoking, alcohol consumption, physical activity, intake of meat and sausage, intake of salad and vegetables, intake of whole-grain bread, coffee consumption); (3) models additionally adjusted for components of the metabolic syndrome (waist circumference, blood pressure, triglycerides, level of HDL-cholesterol). Thus, in models 2 and 3 lifestyle factors and cardiometabolic factors as possible mediators of the association between SES and diabetes incidence are included in order to look for possible pathways between SES and diabetes incidence.

The covariables were dichotomized as follows: age at baseline: 55-64 and 65-74 years; family status: living with a partner / living alone; smoking: current smokers / ex- and non-smokers; high alcohol intake: $>40 \mathrm{~g} /$ day in men, $>20 \mathrm{~g} /$ day in women; high physical activity: at least one hour of sports per week during leisure time in either summer or winter; large waist circumference $\geq 102 \mathrm{~cm}$ and $\geq 88 \mathrm{~cm}$ for men and women, respectively; hypertension: blood pressure of 140 / $90 \mathrm{mmHg}$ or higher, or antihypertensive medication, given that the subjects were aware of being hypertensive; low HDLcholesterol: $<40 \mathrm{mg} / \mathrm{dl}$ in males, $<50 \mathrm{mg} / \mathrm{dl}$ in women; hypertriglyceridemia $\geq 2.0 \mathrm{mmol} / \mathrm{l}$; intake of meat and sausage (intake of meat, sausage or ham almost daily or several times a week); intake of salad and vegetables (intake of salad, cooked or uncooked vegetables almost daily or several times a week); intake of whole-grain bread (intake of whole-grain bread, brown bread or crispbread almost daily or several times a week); coffee consumption (more than three cups of coffee a day).

In addition to the logistic regression models, linear regression models were fitted using change of 2 hour glucose between baseline and follow-up as outcome variable, and 2 hour glucose at baseline was included in the models. 
The level of statistical significance was 5\%. The analyses were carried out using SAS version 9.1.3 (SAS institute, Cary, NC, USA).

\section{Results}

For males, only few significant differences were found between the socioeconomic status groups (table 1). Men in higher SES groups were taller and were more physically active than men in lower SES groups. Wine intake was higher in the high SES group, whereas the proportion of current smokers was slightly lower in the high SES group. Moreover, social status groups of male participants did not differ in the various components of the metabolic syndrome. In women, as opposed to men, overweight was significantly more common in the low SES group. However, the proportion of overweight women with a body mass index larger than $25 \mathrm{~kg} / \mathrm{m}^{2}$ was also rather high in the high SES group (62\% compared to $82 \%$ in the low SES group). Smoking and alcohol intake were more common in women of higher SES. Concerning other components of the metabolic syndrome like HDLcholesterol, triglycerides, and blood pressure, there were no significant differences in women. For subjective physical health, clear differences were found between the SES groups for both sexes. Thirty-one percent of low SES males, $19 \%$ of medium SES males, but only $12 \%$ of high SES males considered their health status as less good or even bad $(\mathrm{p}=0.02)$. For females, the corresponding figures were $26 \%, 20 \%$ and $11 \%$, respectively $(\mathrm{p}=0.10)$.

Subjects did not differ in their median of the Helmert scores with regard to incident diabetes (in men: both median $=14$ for subjects with and without diabetes, $\mathrm{p}=0.95$; in women: median $=12$ for subjects without and median=13 for subjects with diabetes, $\mathrm{p}=0.68$ ). 
Table 1 Baseline characteristics of status groups (global Helmert index) by sex: KORA S4/F4 (Augsburg, Southern Germany) ${ }^{\text {a }}$

\begin{tabular}{|c|c|c|c|c|c|c|c|c|}
\hline & \multicolumn{4}{|c|}{ Males } & \multicolumn{4}{|c|}{ Females } \\
\hline & Low SES & $\begin{array}{l}\text { Medium } \\
\text { SES }\end{array}$ & High SES & $\mathrm{P}$ value ${ }^{\mathrm{b}}$ & $\begin{array}{l}\text { Low } \\
\text { SES }\end{array}$ & $\begin{array}{l}\text { Medium } \\
\text { SES }\end{array}$ & $\begin{array}{l}\text { High } \\
\text { SES } \\
\end{array}$ & $\mathrm{P}$ value ${ }^{\mathrm{b}}$ \\
\hline $\mathrm{N}$ & 49 & 284 & 115 & & 106 & 286 & 45 & \\
\hline Age (years) & $64.7(5.1)$ & $63.3(5.5)$ & $63.1(5.7)$ & 0.21 & $\begin{array}{l}64.0 \\
(5.0)\end{array}$ & $62.7(5.2)$ & $\begin{array}{l}62.6 \\
(6.2)\end{array}$ & 0.07 \\
\hline Body length $(\mathrm{cm})$ & $\begin{array}{l}169.7 \\
(4.9)\end{array}$ & $172.0(6.3)$ & $\begin{array}{l}174.3 \\
(6.4)\end{array}$ & $0.0001 * *$ & $\begin{array}{l}157.4 \\
(5.3)\end{array}$ & $\begin{array}{l}159.9 \\
(5.9)\end{array}$ & $\begin{array}{l}161.5 \\
(5.9)\end{array}$ & $0.0001 * *$ \\
\hline BMI $\left(\mathrm{kg} / \mathrm{m}^{2}\right)$ & $28.6(3.7)$ & $28.0(3.4)$ & $27.9(3.2)$ & 0.40 & $\begin{array}{l}29.5 \\
(4.8)\end{array}$ & $27.9(4.5)$ & $\begin{array}{l}26.3 \\
(3.7)\end{array}$ & $0.0001 * *$ \\
\hline $\begin{array}{l}\text { Overweights } \\
(\mathrm{BMI} \geq 25)(\%)\end{array}$ & 87.8 & 82.8 & 84.8 & 0.64 & 82.1 & 75.5 & 62.2 & $0.03 *$ \\
\hline $\begin{array}{l}\text { Waist } \\
\text { circumference } \\
(\mathrm{cm})\end{array}$ & $\begin{array}{l}101.6 \\
(9.7)\end{array}$ & $99.4(9.0)$ & $99.6(8.6)$ & 0.28 & $\begin{array}{l}92.0 \\
(11.7)\end{array}$ & $\begin{array}{l}88.6 \\
(10.1)\end{array}$ & $\begin{array}{l}84.8 \\
(8.8)\end{array}$ & $0.0003 * *$ \\
\hline $\begin{array}{l}\text { Alcohol intake } \\
>0 \text { g/day }(\%)\end{array}$ & 83.3 & 87.3 & 87.0 & 0.76 & 57.6 & 66.4 & 75.6 & 0.08 \\
\hline $\begin{array}{l}\text { Beer intake } \\
>0 \mathrm{~g} / \text { day }(\%)\end{array}$ & 77.1 & 78.5 & 71.3 & 0.31 & 31.1 & 37.8 & 24.4 & 0.15 \\
\hline $\begin{array}{l}\text { Wine intake } \\
>0 \mathrm{~g} / \text { day }(\%)\end{array}$ & 29.2 & 38.9 & 65.2 & $0.0001 * *$ & 33.0 & 43.7 & 62.2 & $0.004 * *$ \\
\hline $\begin{array}{l}\text { Current smokers } \\
(\%)\end{array}$ & 16.7 & 15.9 & 12.2 & 0.61 & 3.8 & 11.5 & 11.1 & 0.06 \\
\hline $\begin{array}{l}\text { Systolic blood } \\
\text { pressure }(\mathrm{mmHg})\end{array}$ & $\begin{array}{l}138.0 \\
(19.3)\end{array}$ & $138.4(17.4)$ & $\begin{array}{l}136.2 \\
(18.8)\end{array}$ & 0.53 & $\begin{array}{l}128.5 \\
(18.4)\end{array}$ & $\begin{array}{l}127.8 \\
(18.8)\end{array}$ & $\begin{array}{l}129.8 \\
(16.8)\end{array}$ & 0.78 \\
\hline $\begin{array}{l}\text { Diastolic blood } \\
\text { pressure }(\mathrm{mmHg})\end{array}$ & $\begin{array}{l}80.2 \\
(11.2)\end{array}$ & $82.0(9.7)$ & $\begin{array}{l}83.8 \\
(10.6)\end{array}$ & 0.10 & $\begin{array}{l}77.0 \\
(10.0)\end{array}$ & $77.3(9.7)$ & $\begin{array}{l}77.3 \\
(9.1)\end{array}$ & 0.95 \\
\hline $\begin{array}{l}\text { HDL-Cholesterol } \\
(\mathrm{mg} / \mathrm{dl})\end{array}$ & $\begin{array}{l}55.5 \\
(13.9)\end{array}$ & $53.1(13.1)$ & $\begin{array}{l}55.1 \\
(14.7)\end{array}$ & 0.28 & $\begin{array}{l}64.0 \\
(16.6)\end{array}$ & $\begin{array}{l}64.2 \\
(16.8)\end{array}$ & $\begin{array}{l}69.5 \\
(18.3)\end{array}$ & 0.14 \\
\hline $\begin{array}{l}\text { LDL-Cholesterol } \\
(\mathrm{mg} / \mathrm{dl})\end{array}$ & $\begin{array}{l}145.7 \\
(37.2)\end{array}$ & $155.7(36.5)$ & $\begin{array}{l}149.8 \\
(41.5)\end{array}$ & 0.13 & $\begin{array}{l}158.3 \\
(43.0)\end{array}$ & $\begin{array}{l}156.1 \\
(39.9)\end{array}$ & $\begin{array}{l}156.3 \\
(44.8)\end{array}$ & 0.90 \\
\hline $\begin{array}{l}\text { Triglycerides } \\
(\mathrm{mg} / \mathrm{dl})\end{array}$ & $\begin{array}{l}141.5 \\
(105.3)\end{array}$ & $\begin{array}{c}139.2 \\
(79.5)\end{array}$ & $\begin{array}{l}135.9 \\
(80.8)\end{array}$ & 0.91 & $\begin{array}{l}123.1 \\
(53.6)\end{array}$ & $\begin{array}{l}116.8 \\
(54.4)\end{array}$ & $\begin{array}{l}105.1 \\
(50.3)\end{array}$ & 0.17 \\
\hline $\begin{array}{l}\text { Physically active } \\
(\%)\end{array}$ & 27.1 & 45.6 & 49.6 & $0.03 *$ & 34.9 & 53.9 & 57.8 & $0.002 * *$ \\
\hline $\begin{array}{l}\text { Less good or bad } \\
\text { subjective health } \\
\text { status (\%) }\end{array}$ & 31.3 & 19.1 & 12.2 & $0.02 *$ & 26.4 & 20.3 & 11.1 & 0.10 \\
\hline
\end{tabular}


Table 2 shows the results of crude analyses of the associations between SES and diabetes / (pre)diabetes. The proportion of incident diabetes cases was slightly higher for high SES groups, with the exception of the subjective social status, where most incident diabetes cases were found for the low status group. The proportion of incident (pre)diabetes cases among subjects with baseline normoglycemia was lowest in the high status groups for all five SES measures.

Table 2 Incidence of diabetes and (pre)diabetes ${ }^{\mathrm{a}}$ by level of different SES measures: KORA S4/F4 (Augsburg, Southern Germany)

\begin{tabular}{|c|c|c|c|c|c|c|}
\hline & $\begin{array}{c}\text { All } \\
\text { subjects }\end{array}$ & $\begin{array}{c}\text { Incident } \\
\text { diabetes } \\
\text { cases }\end{array}$ & $\underset{\text { value }^{\mathrm{e}}}{\mathbf{p}}$ & $\begin{array}{c}\text { Subjects with } \\
\text { normoglycemia } \\
\text { at baseline }\end{array}$ & $\begin{array}{c}\text { Incident } \\
\text { (pre)diabetes }^{\text {a }} \\
\text { cases }\end{array}$ & $\underset{\text { value }^{\mathrm{e}}}{\mathbf{p}}$ \\
\hline \multicolumn{7}{|l|}{$\begin{array}{l}\text { Global } \\
\text { socioeconomic } \\
\text { status }^{b}\end{array}$} \\
\hline Low & 155 & $13(8.4 \%)$ & & 113 & $32(28.3 \%)$ & \\
\hline Medium & 570 & $59(10.4 \%)$ & & 416 & $118(28.4 \%)$ & \\
\hline High & 160 & $21(13.1 \%)$ & 0.38 & 118 & $24(20.3 \%)$ & 0.21 \\
\hline \multicolumn{7}{|l|}{ Education $^{c}$} \\
\hline Low & 482 & $49(10.2 \%)$ & & 354 & $100(28.3 \%)$ & \\
\hline Medium & 276 & $28(10.1 \%)$ & & 204 & $53(26.0 \%)$ & \\
\hline High & 128 & $16(12.5 \%)$ & 0.73 & 90 & $22(24.4 \%)$ & 0.71 \\
\hline \multicolumn{7}{|l|}{ Income $^{c}$} \\
\hline Low & 263 & $26(9.9 \%)$ & & 196 & $59(30.1 \%)$ & \\
\hline Medium & 392 & $37(9.4 \%)$ & & 285 & $77(27.0 \%)$ & \\
\hline High & 186 & $25(13.4 \%)$ & 0.32 & 132 & $28(21.2 \%)$ & 0.20 \\
\hline \multicolumn{7}{|l|}{$\begin{array}{l}\text { Occupational } \\
\text { status }\end{array}$} \\
\hline Low & 323 & $35(10.8 \%)$ & & 232 & $60(25.9 \%)$ & \\
\hline Medium & 324 & $29(9.0 \%)$ & & 236 & $68(28.8 \%)$ & \\
\hline High & 220 & $28(12.7 \%)$ & 0.37 & 163 & $40(24.5 \%)$ & 0.60 \\
\hline \multicolumn{7}{|l|}{$\begin{array}{l}\text { Subjective } \\
\text { social status }^{d}\end{array}$} \\
\hline Low & 248 & $39(15.7 \%)$ & & 173 & $42(24.3 \%)$ & \\
\hline Medium & 522 & $43(8.2 \%)$ & & 392 & $114(29.1 \%)$ & \\
\hline High & 92 & $9(9.8 \%)$ & $0.01 *$ & 63 & $10(15.9 \%)$ & 0.07 \\
\hline
\end{tabular}

$* \mathrm{p}<0.05$

a (Pre)diabetes means prediabetes (IFG/IGT) or diabetes

${ }^{\mathrm{b}}$ Global socioeconomic status groups were built according to Helmert scores (low: 2-8, medium 9-18, high 1927)

${ }^{c}$ Helmert scores for education, income and occupational status were classified into three groups (low: up to 3, medium: 4-6, high: 7-9)

${ }^{\mathrm{d}}$ Self-assessments were categorized into three groups (low subjective status (lower or working class), medium subjective status (medium class), high subjective status (upper medium or upper class))

${ }^{\mathrm{e}} \chi^{2}$-test 
Table 3 presents the results of multivariate logistic regressions fitting diabetes risks of subjects who were normoglycemic or prediabetic at baseline. The risk of diabetes in the seven year follow-up was neither associated with the global SES nor with educational level, income and occupational status. In model 1 adjusted only for age and sex, subjects with low global SES did not have a larger risk of diabetes than subjects with high global SES (OR: 0.7; 95\%CI: 0.3-1.6). Additional adjusting for lifestyle factors (model 2) and for components of the metabolic syndrome (model 3) had only small impacts on the odds ratios. So, for global SES, education, income and occupational status odds ratios were one or even smaller than one. Subjects with low subjective SES had a somewhat increased risk of diabetes than subjects with high subjective SES which was nevertheless not significant (OR: 1.7; 95\%CI: 0.8-3.7) and which decreased upon including possible mediators. In linear regression models with changes in $2 \mathrm{~h}$-glucose between baseline and follow-up as outcome variable, there were no significant relationships between SES and changes in $2 \mathrm{~h}$-glucose for all SES measures (data not shown).

Table 4 presents models which predict the risk of (pre)diabetes of subjects with baseline normoglycemia. Except for occupational status, the odds ratios were all larger than one, indicating that the risk of (pre)diabetes is higher for low as compared with high SES groups. Some odds ratios showed a borderline significance, but just one odds ratio reached the level of statistical significance. Subjects with medium subjective social status had a significantly increased (pre)diabetes risk in the model adjusted for age and sex (OR: 2.2; 95\%-CI: 1.1-4.5). The odds ratios were slightly reduced after adjusting for further variables.

In the regression models in tables 3 and 4, interaction terms of SES and sex were not statistically significant and, therefore, were excluded from the models. In addition, sex-specific regression models were fitted, which showed results for the association of SES and diabetes / (pre)diabetes incidence which were comparable with the results without stratification by sex (data not shown). 
Table 3 Association of SES measures with type 2 diabetes incidence in the follow-up: multivariate logistic regression analyses with 887 subjects without diabetes at baseline (low and medium SES group, respectively, versus high SES group, odds ratios with $95 \%$ confidence intervals; dependent variable $=$ diabetes incidence in the follow-up)

\begin{tabular}{|c|c|c|c|c|}
\hline & & Model 1 ${ }^{\mathrm{a}}$ & Model $2^{b}$ & Model $3^{c}$ \\
\hline \multirow[t]{4}{*}{ Global SES } & low SES & $\begin{array}{c}0.7 \\
(03-16)\end{array}$ & $\begin{array}{c}0.6 \\
(03-13)\end{array}$ & $\begin{array}{c}0.6 \\
(02-12)\end{array}$ \\
\hline & medium SES & 0.9 & 0.8 & 0.8 \\
\hline & & $(0.5-1.5)$ & $(0.5-1.4)$ & $(0.4-1.4)$ \\
\hline & high SES (ref) & 1 & 1 & 1 \\
\hline \multirow[t]{5}{*}{ Education } & low SES & 0.9 & 0.8 & 0.8 \\
\hline & & $(0.5-1.7)$ & $(0.4-1.6)$ & $(0.4-1.6)$ \\
\hline & medium SES & 0.9 & 0.9 & 0.9 \\
\hline & & $(0.5-1.8)$ & $(0.4-1.7)$ & $(0.4-1.8)$ \\
\hline & high SES (ref) & 1 & 1 & 1 \\
\hline \multirow[t]{4}{*}{ Income } & low SES & 0.7 & 0.6 & 0.6 \\
\hline & & $(0.4-1.2)$ & $(0.3-1.2)$ & $(0.3-1.1)$ \\
\hline & medium SES & $\begin{array}{c}0.0 \\
(0.4-1.1)\end{array}$ & $\begin{array}{c}0.1 \\
(0.4-1.2)\end{array}$ & $\begin{array}{c}0.1 \\
(0.4-1.2)\end{array}$ \\
\hline & high SES (ref) & 1 & 1 & 1 \\
\hline \multirow[t]{4}{*}{$\begin{array}{l}\text { Occupational } \\
\text { status }\end{array}$} & low SES & $\begin{array}{c}1.0 \\
(0.6-1.7)\end{array}$ & $\begin{array}{c}0.9 \\
(0.5-1.5)\end{array}$ & $\begin{array}{c}0.9 \\
(0.5-1.6)\end{array}$ \\
\hline & medium SES & 0.8 & 0.7 & 0.8 \\
\hline & & $(0.4-1.3)$ & $(0.4-1.3)$ & $(0.5-1.5)$ \\
\hline & high SES (ref) & 1 & 1 & 1 \\
\hline \multirow{5}{*}{$\begin{array}{l}\text { Subjective } \\
\text { social status }\end{array}$} & low SES & 1.7 & 1.5 & 1.4 \\
\hline & & $(0.8-3.7)$ & $(0.7-3.4)$ & $(0.6-3.2)$ \\
\hline & medium SES & 0.9 & 0.8 & 0.8 \\
\hline & & $(0.4-1.9)$ & $(0.4-1.7)$ & $(0.4-1.8)$ \\
\hline & high SES (ref) & 1 & 1 & 1 \\
\hline
\end{tabular}

${ }^{\mathrm{a}}$ Model 1: adjusted for age and sex

${ }^{\mathrm{b}}$ Model 2: like Model 1, + smoking, alcohol intake, physical activity and diet (intake of meat and sausage, of salad and vegetables, of whole-grain bread, and coffee consumption)

${ }^{\mathrm{c}}$ Model 3: like Model 2, + blood pressure, hypertriglyceridemia, waist circumference, HDL-Cholesterol 
Table 4 Association of SES measures with (pre)diabetes ${ }^{\mathrm{a}}$ incidence in the follow-up: multivariate logistic regression analyses with 649 subjects with normoglycemia at baseline (low and medium SES group, respectively, versus high SES group, odds ratios with 95\% confidence intervals; dependent variable $=($ pre $)$ diabetes $^{\mathrm{a}}$ incidence in the follow-up)

\begin{tabular}{|c|c|c|c|c|}
\hline & & Model $1^{\text {b }}$ & Model $2^{c}$ & Model 3 ${ }^{\mathrm{d}}$ \\
\hline \multirow[t]{4}{*}{ Global SES } & low SES & $\begin{array}{c}1.6 \\
(08-29)\end{array}$ & $\begin{array}{c}1.3 \\
(07-25)\end{array}$ & $\begin{array}{c}1.1 \\
(0.6-22)\end{array}$ \\
\hline & medium SES & 1.6 & 1.5 & 1.4 \\
\hline & & $(0.96-2.6)$ & $(0.9-2.5)$ & $(0.8-2.3)$ \\
\hline & high SES (ref) & 1 & 1 & 1 \\
\hline \multirow[t]{4}{*}{ Education } & low SES & $\begin{array}{c}1.2 \\
(0.7-2.1)\end{array}$ & $\begin{array}{c}1.1 \\
(0.6-2.0)\end{array}$ & $\begin{array}{c}1.1 \\
(06-2.0)\end{array}$ \\
\hline & medium SES & 1.1 & 1.1 & 1.1 \\
\hline & & $(0.6-2.0)$ & $(0.6-2.0)$ & $(0.6-2.0)$ \\
\hline & high SES (ref) & 1 & 1 & 1 \\
\hline \multirow[t]{4}{*}{ Income } & low SES & $\begin{array}{c}1.5 \\
(0.9-2.6)\end{array}$ & $\begin{array}{c}1.4 \\
(0.8-2.3)\end{array}$ & $\begin{array}{c}1.2 \\
(0.7-2.1)\end{array}$ \\
\hline & medium SES & 1.3 & 1.3 & 1.3 \\
\hline & & $(0.8-2.1)$ & $(0.8-2.1)$ & $(0.8-2.2)$ \\
\hline & high SES (ref) & 1 & 1 & 1 \\
\hline \multirow{4}{*}{$\begin{array}{l}\text { Occupational } \\
\text { status }\end{array}$} & low SES & $\begin{array}{c}1.1 \\
(0.7-1.8)\end{array}$ & $\begin{array}{c}1.0 \\
(0.6-1.6)\end{array}$ & $\begin{array}{c}1.0 \\
(0.6-1.6)\end{array}$ \\
\hline & medium SES & 1.3 & 1.4 & 1.4 \\
\hline & & $(0.8-2.1)$ & $(0.9-2.2)$ & $(0.9-2.3)$ \\
\hline & high SES (ref) & 1 & 1 & 1 \\
\hline \multirow{4}{*}{$\begin{array}{l}\text { Subjective } \\
\text { social status }\end{array}$} & low SES & $\begin{array}{c}1.7 \\
(0.8-3.6)\end{array}$ & $\begin{array}{c}1.4 \\
(0.6-3.0)\end{array}$ & $\begin{array}{c}1.2 \\
(0.6-2.7)\end{array}$ \\
\hline & medium SES & 2.2 & 1.9 & 1.8 \\
\hline & & $(1.1-4.5)$ & $(0.9-4.0)$ & $(0.9-3.8)$ \\
\hline & high SES (ref) & 1 & 1 & 1 \\
\hline \multicolumn{5}{|c|}{${ }^{\mathrm{a}}(\mathrm{Pre})$ diabetes means prediabetes or type 2 diabetes } \\
\hline \multicolumn{5}{|c|}{ bodel 1: adjusted for age and sex } \\
\hline \multicolumn{5}{|c|}{$\begin{array}{l}{ }^{c} \text { Model 2: like Model } 1,+ \text { smoking, alcohol intake, physical activity and diet (intake of meat and sausage, of } \\
\text { salad and vegetables, of whole-grain bread, and coffee consumption) }\end{array}$} \\
\hline
\end{tabular}

\section{Discussion}

Our study showed that objective SES measures (global Helmert index, income, occupation, educational level) were not associated with type 2 diabetes incidence in an elderly population in a statistically significant way. Among subjects with normoglycemia at baseline, there were more cases of incident (pre)diabetes in the low SES group than in the high SES group, but these associations were not significant for the various measures of objective SES. When using subjective social status instead 
of objective measures of social status, we found stronger relationships between diabetes and (pre)diabetes, respectively, and social status.

The lack of a relationship between objective SES and diabetes incidence in our study is not in line with the literature where inverse relationships were reported.[1-15]However, our study differed from the published studies in one important aspect: we have investigated an elderly population aged 55 to 74 years at baseline whereas in most other studies (exceptions [8-11] see below) either middle-aged study populations or cohorts comprising several age groups were investigated. In the Health and Retirement Study with subjects aged 51 years and older a negative impact of low SES on diabetes onset was shown only for women.[8] A US American study comparing two cohorts of middle-aged (51-61 years) and older adults (>70 years) found that effects of social status were reduced in the elderly cohort.[11] This suggests that old age has an important impact on the association between SES and diabetes incidence. To explain the lack of an association between the objective SES and diabetes incidence and the stronger association between the subjective SES and diabetes risk, three explanations are conceivable:

(1) An accurate measurement of objective SES is problematic in the elderly for several reasons.[27] Links between working conditions and health as captured by the occupational status may still influence health in old age, but may also be attenuated after retirement. To give a second example, in old age income is often drawn from several sources and is, therefore, more difficult to measure accurately. However, it was suggested that the subjective SES is a more sensitive measure of social status capturing more nuances of the socioeconomic position and of life-time achievement.[17, 28] Accordingly, in a cross-sectional study in six European countries with subjects aged between 50 and 65 years, subjective SES was shown to be stronger related to health outcome than income.[29] Studies about subjective SES and diabetes in old age are rare; with cross-sectional data of the English Longitudinal Study of Ageing, a strong relation between subjective SES and diabetes prevalence was found.[17] In our study, only one in four odds ratios for the association between subjective SES and the incidence of diabetes/(pre)diabetes was statistically significant, and the (pre)diabetes risk was 
larger for subjects with medium subjective SES than for subjects with low subjective SES (compared to high subjective SES). In the light of these results, it is suggested that the association between subjective SES and diabetes in the elderly should be further investigated.

(2) Apart from problems of measuring SES, there are other factors possibly contributing to a weaker relationship between SES and health status in the KORA cohort. Most subjects born in the 1930s and 1940s in Germany had a similar (low) school education. Thus, in that age group, subjects with low levels of formal education were not that underprivileged as it is the case today, and thus lower education probably had less negative impacts on health. Moreover, as can be seen from table 1 , differences between status groups are not much pronounced in many regards.

(3) Subjects developing diabetes in the follow-up already had much larger fasting and $2 \mathrm{~h}$-glucose concentrations at baseline (data not shown), and accordingly, most subjects with diabetes in the follow-up had prediabetes at baseline. In addition, subjects getting the disease in the follow-up also had more adverse metabolic risk factors (HDL-cholesterol, adiponectin, serum uric acid,data not shown) at baseline than subjects without diabetes in the follow-up. Not all the subjects with increased glucose values at baseline finally developed diabetes, but these results support the assumption that the development of diabetes is determined by risk factors acting long before the onset of the disease. Thus, in older subjects with adverse clinical data at baseline, SES may have less influence on the progression towards diabetes.

One might argue that the KORA population is not representative. There might have been a selection bias due to earlier death and lower response rates of less wealthy and less healthy people resulting in more homogeneous elderly populations, leading to an attrition of the SES-health relationship. Moreover, some characteristics of the population seem to be somewhat unusual: high SES women show an elevated level of smoking and alcohol consumption compared to low SES women, and in men, there is a lack of differences in the metabolic profiles between the SES groups. However, for SES differences concerning alcohol and smoking in women, and metabolic syndrome components in 
men there is little data for the elderly. In Germany, it was shown that consumption of alcohol is elevated in women with high SES.[30]

Some limitations may have affected our results. First, there was a healthy participant effect. The 336 non-participants were less healthy and had a lower social status than the 887 participants included here (data not shown). If there were more diabetes cases in the subjects lost to follow-up the influence of low SES on diabetes incidence would have been underestimated. Second, the number of incident diabetes cases was quite small for the low / high levels of some SES measures. However, our results were consistent for all objective SES measures; using a continuous variable as SES measure allowed the comparisons of much larger groups (e.g., 60 diabetic versus 387 non-diabetic subjects in men) and also showed no differences in subjects with and without diabetes.

Our study has several strengths. It was based on a well-defined population, and we used several different SES measures in the analyses. Our analyses were adjusted for lifestyle factors and for components of the metabolic syndrome, and, contrary to most other studies, [3,5,7-11,15] diabetes incidence was assessed by OGTT in addition to validated self-reports.

In conclusion, this study suggests that the inverse association between objective SES and diabetes incidence which was found for younger and middle-aged populations [1-15] cannot be taken for granted for elderly populations. For this age group, the exact nature of the association between SES and diabetes incidence needs further investigation. 


\section{What is known on this subject}

Several studies found an inverse association between the socioeconomic status and the incidence of diabetes in younger and middle-aged populations. However, there is not much evidence concerning the question whether this association also holds true for elderly populations.

\section{What this study adds}

This study shows that an inverse relationship between the objective socioeconomic status and diabetes incidence cannot simply be taken for granted in elderly populations. For a German cohort of 55 to 74 year old subjects an inverse association between SES and diabetes incidence was not found neither for men nor for women. Elderly people developing a new type 2 diabetes display an adverse metabolic risk profile years before the onset of diabetes so that a strong force for diabetes seems to outweigh the potential influence of the socioeconomic status.

\section{Public health implications}

This study supports the claim that health inequalities have to be studied for each age group separately. It suggests that health inequalities in older age groups could be less pronounced than in younger age groups, and that this lack of an association between socioeconomic status and health is very well compatible with the fact that these associations are found earlier in the life course. 


\section{Acknowledgments}

The Diabetes Cohort Study was funded by a German Research Foundation project grant to the corresponding author (DFG; RA 459/2-1). The German Diabetes Center is funded by the German Federal Ministry of Health, and the Ministry of School, Science and Research of the State of NorthRhine-Westfalia. The KORA research platform and the KORA Augsburg studies are financed by the Helmholtz Zentrum München, German Research Center for Environmental Health, which is funded by the German Federal Ministry of Education, Science, Research and Technology and by the State of Bavaria. We thank the field staff in Augsburg who were involved in the conduct of the studies.

\section{Duality of interest}

The authors declare that there is no duality of interest associated with this paper. 


\section{References}

1. Barker DJP, Gardner MJ, Power C. Incidence of diabetes amongst people aged 18-50 years in nine British towns: A collaborative study. Diabetologia 1982; 22: 421-5.

2. Haffner SM, Hazuda HP, Mitchell BD et al. Increased incidence of type II diabetes mellitus in Mexican Americans. Diabetes Care 1991; 14: 102-8.

3. Lipton RB, Liao Y, Cao G et al. Determinants of incident non-insulin-dependent diabetes mellitus among blacks and whites in a national sample: The NHANES I Epidemiologic Follow-up Study. Am J Epidemiol 1993; 138: 826-39.

4. Morikawa Y, Nakagawa H, Ishizaki M et al. Ten-year follow-up study on the relation between the development of non-insulin-dependent diabetes mellitus and occupation. Am J Ind Med 1997; 31: 80-4.

5. Resnick HE, Valsania P, Halter JB et al. Differential effects of BMI on diabetes risk among black and white Americans. Diabetes Care 1998; 21: 1828-35.

6. Burke JP, Williams K, Gaskill SP et al. Rapid rise in the incidence of type 2 diabetes from 1987 to 1996. Arch Intern Med. 1999; 159: 1450-6.

7. Kumari M, Head J, Marmot M. Prospective study of social and other risk factors for incidence of type 2 diabetes in the Whitehall II Study. Arch Intern Med 2004; 164: 1873-80.

8. Best LE, Hayward MD, Hidajat MM. Life course pathways to adult-onset diabetes. Soc Biol 2005; 52: 94-111.

9. Maty SC, Everson-Rose SA, Haan MN et al. Education, income, occupation, and the 34-year incidence (1965-99) of type 2 diabetes in the Alameda County Study. Int J Epidemiol 2005; 34: $1274-81$.

10. Robbins JM, Vaccarino V, Zhang H et al. Socioeconomic status and diagnosed diabetes incidence. Diabetes Res Clin Pract 2005; 68: 230-6.

11. Wray LA, Alwin DF, McCammon RJ et al. Social status, risky health behaviors, and diabetes in middle-aged and older adults. J Gerontol B Psychol Sci Soc Sci 2006; 61: 290-8. 
12. Cox M, Boyle PJ, Davey PG et al. Locality deprivation and type 2 diabetes incidence: A local test of relative inequalities. Soc Sci Med 2007; 65: 1953-64.

13. Lidfeldt J, Li TY, Hu FB et al. A prospective study of childhood and adult socioeconomic status and incidence of type 2 diabetes in women. Am J Epidemiol 2007; 165: 882-9.

14. Valdés S, Botas P, Delgado E et al. Population-based incidence of type 2 diabetes in Northern Spain: The Asturias Study. Diabetes Care 2007; 30: 2258-63.

15. Maty SC, Lynch JW, Raghunathan TE et al. Childhood socioeconomic position, gender, adult body mass index, and incidence of type 2 diabetes mellitus over 34 years in the Alameda County Study. Am J Public Health 2008; 98: 1486-94.

16. Geyer S, Hemström Ö, Peter R et al. Education, income, and occupational class cannot be used interchangeably in social epidemiology. Empirical evidence against a common practice. $J$ Epidemiol Community Health 2006; 60: 804-10.

17. Demakakos P, Nazroo J, Breeze E et al. Socioeconomic status and health: the role of subjective social status, Soc Sci Med 2008; 67: 330-340.

18. Rathmann W, Strassburger K, Heier M et al. Incidence of type 2 diabetes in the elderly German population and the effect of clinical and lifestyle risk factors: KORA S4/F4 cohort study. Diab Med 2009; 26: 1212-1219.

19. Rathmann W, Haastert B, Icks A et al. High prevalence of undiagnosed diabetes mellitus in Southern Germany: Target populations for efficient screening. The KORA survey 2000.

Diabetologia 2003; 46: 182-9.

20. Helmert U, Mielck A, Shea S. Poverty and health in West Germany. Soz Präventivmed 1997; 42: $276-85$.

21. Helmert U. Soziale Ungleichheit und Krankheitsrisiken. Augsburg: Maro. 2003.

22. Helmert U, Shea S. Social inequalities and health status in Western Germany. Public Health 1994; 108: 341-56. 
23. Alberti KGMM, Zimmet PZ, for the WHO Organization. Definition, diagnosis and classification of diabetes mellitus and its classifications. Part 1: Diagnosis and classification of diabetes mellitus. Provisional report of a WHO consultation. Diabet Med 1998; 15: 539-53.

24. Winkler G, Döring A. Validation of a short qualitative food frequency list used in several German large scale surveys. Z Ernaehrungswiss 1998; 37 (3): 234-241.

25. Tang M, Chen Y, Krewski D. Gender-related differences in the association between socioeconomic status and self-reported diabetes. Int J Epidemiol 2003; 32: 381-5.

26. Rathmann W, Haastert B, Icks A et al. Sex differences in the associations of socioeconomic status with undiagnosed diabetes mellitus and impaired glucose tolerance in the elderly population: the KORA Survey 2000. Eur J Public Health 2005; 15: 627-33.

27. Grundy E, Holt G. The socioeconomic status of older adults: How should we measure it in studies of health inequalities? J Epidemiol Community Health 2001; 55: 895-904.

28. Singh-Manoux A, Marmot M, Adler NE. Does subjective social status predict health and change in health status better than objective status? Psychosom Med 2005; 67: $855-861$

29. Theodossiou I, Zangelidis A. The social gradient in health: The effect of absolute income and subjective social status assessment on the individual's health in Europe. Econ Hum Biol 2009; 7: 229-237.

30. Baumeister S, Alte D, Meyer C et al. Riskanter Alkoholkonsum und alkoholbezogene Störungen in Vorpommern: Die Studie ,Leben und Gesundheit in Vorpommern ‘ (SHIP) und der Bundesgesundheitssurvey 1998 im Vergleich. Gesundheitswesen 2005; 67: 39-47. 